\title{
Prophylactic oophorectomy
}

\author{
Wouter J. Meijer ${ }^{a}$ and Arnold C.M. van Lindert ${ }^{b}$ \\ ${ }^{a}$ Netherland Institute of Primary Health Care, Utrecht, Netherlands and ${ }^{b}$ Department of Obstetrics and Gynecology, Academic \\ Hospital Utrecbt, Utrecht, Netherlands \\ Accepted for publication 7 July 1992
}

\section{Summary}

The risks and benefits of prophylactic bilateral oophorectomy (BO) accompanying hysterectomy are reviewed. The potential reduction in the risk of subsequent ovarian cancer is quantified using literature data and a mathematical model. The risks of subsequent breast cancer from low-dose ERT are estimated using a comprehensive mathematical model. It is hypothesized that $\mathrm{BO}$ may have a substantial protective effect on breast cancer risk despite subsequent low-dose or non-low-dose ERT, when BO is performed at an early age. In women with a family history of ovarian cancer or breast cancer, the individual risks must be assessed on the basis of a pedigree analysis. In conclusion, a decision on BO must be based on weighing the potential benefits of reduced ovarian and breast cancer risks against the psychological importance of retaining the ovaries and the risk of osteoporosis and cardiovascular disease when compliance with ERT is less than perfect. The provided quantitative data may help in making the right decision.

Oophorectomy; Hysterectomy; Breast cancer

\section{Introduction}

There is an ongoing debate on the value of prophylactic bilateral oophorectomy (BO) [28,31], but the disavantages and benefits of prophylactic oophorectomy have not been well established. Opinions differ. It is obvious that a prophylactic BO should only be performed or omitted after adequate information, understanding and of course consent. The woman has the ultimate choice. For a rational choice, there must be a reliable estimate of the potential risks and bene-

Correspondence to: W.J. Meijer, Netherlands Institute of Primary Health Care, P.O. Box 1568, 3500 BN, Netherlands. fits of $\mathrm{BO}$. The present article is aimed at quantifying the potential benefits of prophylactic $\mathrm{BO}$ in preventing ovarian and breast cancer by combining existing knowledge and using mathematical models.

\section{Risks of ovarian cancer}

The lifetime risks of ovarian cancer in the general population at various ages are given in Table I (kindly provided by R. Damhuis, Comprehensive Cancer Centre, Rotterdam). These prospective lifetime risks (cumulative risks) of acquiring ovarian cancer were computed by life table analysis using the data on age-specific incidence from the Comprehensive Cancer Centre, 
TABLE I

Estimated lifetime risk of ovarian cancer (\%) in the general population and in women after hysterectomy

\begin{tabular}{lll}
\hline Age & $\begin{array}{l}\text { General } \\
\text { population }\end{array}$ & $\begin{array}{l}\text { After } \\
\text { hysterectomy }\end{array}$ \\
\hline $25-29$ & 1.70 & $0.64-1.70$ \\
$30-34$ & 1.69 & $0.64-1.69$ \\
$35-39$ & 1.66 & $0.63-1.66$ \\
$40-44$ & 1.62 & $0.62-1.62$ \\
$45-49$ & 1.57 & $0.60-1.57$ \\
$50-54$ & 1.48 & $0.56-1.48$ \\
$55-59$ & 1.36 & $0.55-1.36$ \\
$60-64$ & 1.20 & $0.52-1.20$ \\
$65-69$ & 1.02 & $0.39-1.02$ \\
$70-74$ & 0.81 & $0.31-0.81$ \\
$75-79$ & 0.51 & $0.19-0.51$ \\
$80-84$ & 0.26 & $0.10-0.26$ \\
$85+$ & unknown & unknown \\
\hline
\end{tabular}

and on age-specific mortality from the Central Bureau of Statistics (Centraal Bureau voor de Statistiek, CBS) of The Netherlands. The method of calculation is illustrated by Table II: it is shown that in a cohort of 100040 -year old women, 16.2 will acquire ovarian cancer in the course of their lives. Thus, the lifetime risk of ovarian cancer in a 40 -year-old woman is $1.62 \%$.

\section{TABLE II}

The calculation of the number of incident cases in a cohort of 1000 women from age 40 through lifetime (the incidence is 16.2 yielding an average lifetime risk of $1.62 \%$ for a 40 -year-old woman)

\begin{tabular}{llll}
\hline $\begin{array}{l}\text { Age } \\
\text { period }\end{array}$ & $\begin{array}{l}\text { Age-specific } \\
\text { incidence per } \\
1.00000 \\
\text { person-years }\end{array}$ & $\begin{array}{l}\text { Person-years } \\
\text { of cohort in } \\
\text { age period } \\
\text { (approxi- } \\
\text { mation) }\end{array}$ & $\begin{array}{l}\text { Incident cases } \\
\text { of cohort in } \\
\text { age period }\end{array}$ \\
\hline $40-44$ & 11.0 & 4985 & 0.6 \\
$45-49$ & 17.3 & 4940 & 0.9 \\
$50-54$ & 24.0 & 4870 & 1.2 \\
$55-59$ & 36.4 & 4760 & 1.7 \\
$60-64$ & 44.8 & 4600 & 2.1 \\
$65-69$ & 51.4 & 4355 & 2.2 \\
$70-74$ & 65.1 & 3975 & 2.6 \\
$75-79$ & 87.8 & 3375 & 3.0 \\
$80-84$ & 49.7 & 2435 & 1.2 \\
$85+$ & 28.7 & 2400 & 0.7 \\
Total & & & 16.2 \\
\hline
\end{tabular}

From these risks, the lifetime risks of ovarian cancer in women after hysterectomy were estimated (Table I). Hysterectomy (with preservation of the ovaries) is reported to have a protective effect on ovarian cancer risks (relative risk of ovarian cancer by hysterectomy was $0.36(95 \% \mathrm{CI}$ $0.10-0.73)$ in one study [1] and $0.56(95 \% \mathrm{CI}$ $0.38-0.81$ ) in another study [11] This protective effect may be explained by the fact that hysterectomy provides the opportunity to screen for visible ovarian pathology that may be premalignant [11]. It is not known if this protection persists after 20 years after hysterectomy [11], so perhaps at a later age, by development of late ovarian pathology, this protective effect is reduced or neutralized (which would yield a relative risk of 1). Thus, using the most precise estimate [11], the risks in the general population were adjusted for hysterectomy by using a correction factor with range between 0.38 and 1.

The calculated lifetime prospective risks of ovarian cancer (Table I) are much higher than the estimate of $0.2 \%$ which was generally used until recently. This estimate of $0.2 \%$ was based on studies with incomplete long-lasting follow-up of the patients [31]. By using data from population based cancer registries, the more reliable figures in Table I were obtained.

The estimates of the lifetime risks of ovarian cancer risks after hysterectomy (Table I) have a considerable uncertainty range because it is not known by how much exactly the protective effect of hysterectomy reduces cancer risk in the preserved ovaries, and if such an effect persists even after the first 20 years after hysterectomy.

Women with a family history of ovarian cancer are at increased risk for acquiring this disease.

In families with two or more affected close relatives, evidence suggests autosomal dominant inheritance with high penetrance. Thus, in such a high risk family, the daughter or sister of a patient with ovarian cancer has the high ovarian cancer lifetime risk of $10 \%$ at age $40,20 \%$ at age $50,30 \%$ at age 60 and $40 \%$ at age 70 [23]. Prophylactic BO must be considered in these women; it becomes the major clinical modality after the age of 35 [16]. Unfortunately, in these women from high risk families, BO cannot pro- 
tect against the development of intra-abdominal carcinomatosis. In one study prophylactic $\mathrm{BO}$ was performed on 28 members of 16 high risk families; three of these women subsequently developed disseminated intra-abdominal malignancy [32]. The authors concluded that in these high risk families the genetic susceptibility is not limited to ovarian carcinoma but extends to cancers arising in tissues embryologically related to the ovary. The small numbers in this study preclude an estimation of the frequency at which intra-abdominal carcinomatosis occurs in oophorectomized women from ovarian cancer-prone families. In our view it is plausible that, despite this tragic occurrence of intra-abdominal carcinomatosis, removal of a substantial amount of tissue-at-risk (the ovaries) prevents or delays cancer in such women. Clearly, further rcsearch is necessary to establish the effect of prophylactic BO on ovarian cancer risk in these women. Such BO may also have a protective effect on breast cancer, which is important because breast cancer risk is elevated in these families with high ovarian cancer risk.

The risk of ovarian cancer is also increased for a woman who has only one affected first degree relative. In these women, the average cumulative risk of death from ovarian cancer by age 70 is $2.5 \%$ [23]. However, there is heterogeneity in individual risks and therefore, in the individual woman her risk of ovarian cancer can be estimated only by genetic advice with pedigree analysis [17].

\section{Risks of breast cancer}

In a meticulous meta-analysis Steinberg et al. calculated the mean proportional increase in breast cancer risk for each year of estrogen use (various dosages), after bilateral oophorectomy [30]. The resulting relative risk of breast cancer for each year of estrogen use was $1.028(95 \%$ confidence interval (CI) $1.010-1.047$, or 0.028 , 95\% CI $0.010-0.047$, when expressed on a logscale with base $e$ ). This estimate is the basis of our calculations of the breast cancer risk from ERT in oophorectomized women. In our calculations, we combine existing knowledge, using a

\section{TABLE III}

Estimated lifetime risks of breast cancer (\%) after elective hysterectomy, and after natural menopause at age 50

\begin{tabular}{|c|c|c|c|}
\hline \multirow{2}{*}{$\begin{array}{l}\text { Age at } \\
\text { hyster- } \\
\text { ectomy }\end{array}$} & \multicolumn{2}{|c|}{ After BO } & \multirow{2}{*}{$\begin{array}{l}\text { No BO } \\
\text { menopause } \\
\text { before or at } \\
\text { age } 50 \text { and no } \\
\text { ERT }\end{array}$} \\
\hline & no ERT & $\begin{array}{l}\text { ERT until } \\
50 \text { years }\end{array}$ & \\
\hline$\overline{30}$ & 2.2 & 3.1 & $2.2-10.1$ \\
\hline 35 & 3.7 & 4.8 & $3.7-10.0$ \\
\hline 40 & 6.0 & 7.1 & $6.0-9.7$ \\
\hline 45 & 8.0 & 8.7 & $8.0-9.2$ \\
\hline
\end{tabular}

comprehensive mathematical model which was developed by Pike et al. (see Appendix for further details).

Our estimates of breast cancer risk from ERT in oophorectomized women relate to non-lowdose ERT. Low-dose ERT $(0.625 \mathrm{mg}$ of conjugated estrogens or less) is unlikely to increase breast cancer risk [4] and therefore, the increase in breast cancer risk, which was found in the meta-analysis by Steinberg et al., probably reflects the effect of non-low-dose ERT in the various studies.

The estimates of the breast cancer risks from ERT which result from our calculations have a large range of uncertainty, since the underlying estimate of the yearly proportional increase in risk has a wide confidence interval (relative risk $1.028,95 \%$ CI 1.010-1.047); thus the calculated estimates only serve to give a general idea of the potential size of the effect of non-low-dose ERT after BO.

The lifetime risks of breast cancer after elective hysterectomy are shown in Table III. In the category "no BO" (ovaries preserved) the upper values correspond with natural menopause at age 50 (identical to the general population). The lower values correspond with immediate loss of ovarian function after hysterectomy.

A premature loss of ovarian function was found in a subgroup of women who had previously undergone abdominal hysterectomy with bilateral ovarian conservation: in $34 \%$ of the 90 studied women, ovarian failure occurred within two years 


\section{TABLE IV}

Estimated difference in lifetime breast cancer risk in a hysterectomized woman with $\mathrm{BO}$ and ERT, relative to natural menopause without ERT

\begin{tabular}{ll}
\hline $\begin{array}{l}\text { Age at } \\
\text { hysterectomy }\end{array}$ & $\begin{array}{l}\text { Absolute reduction } \\
\text { of lifetime breast } \\
\text { cancer risk (\%) }\end{array}$ \\
\hline 30 & $0-7.9$ \\
35 & $0-6.3$ \\
40 & $0-3.7$ \\
45 & $0-1.2$ \\
\hline
\end{tabular}

(possibly the combined effect of reduced vascular supply to the ovary and impairment of the endocrine contribution of the uterus to normal ovarian function [27]. Such an induced early menopause will reduce breast cancer risk in the hysterectomized, nonoophorectomized woman (according to Pike's model, see Appendix). In the extreme case, hysterectomy with ovarian conservation is immediately followed by loss of ovarian function, which reduces breast cancer risk to the values equal to oophorectomized women (see Appendix).

Table IV presents the resulting (absolute) reduction of lifetime breast cancer risk. The lower values (zero) correspond with the one extreme in which hysterectomy with ovarian conservation is immediately followed by loss of ovarian function, which nullifies the protective effect of $\mathrm{BO}$ on breast cancer risk. The upper values represent the situation in which in a patient (e.g. age 40 years) $\mathrm{BO}$ was performed (minimal lifetime breast cancer risk $6.0 \%$ ) whereas after ovarian conservation her lifetime breast cancer risk would have been $9.7 \%$ (natural menopause), resulting in a protective effect of $3.7 \%$ lifetime breast cancer risk. These estimates (table IV) relate to women who do not have one or more first degree relatives with breast cancer.

It appears from Table IV that the potential reduction in risk strongly depend on the age of hysterectomy. The upper limit of preventable breast cancer risk drops from $7.9 \%$ (at hysterec- tomy a age 30 ) and $6.3 \%$ (hysterectomy at age 35) to $3.7 \%$ (hysterectomy at age 40 ) and $1.2 \%$ (hysterectomy at age 45). Thus, the results from our theoretical calculations suggest that in women who were relatively young at $\mathrm{BO}$, the protective effect of $\mathrm{BO}$ will be partly retained despite subsequent ERT. This conclusion is at variance with the general view that in all (subgroups of) oophorectomizcd women the protective effect of BO on breast cancer risk is neutralized by ERT [34]. However, in the reported study [34] the study groups consisted mainly of women with BO after age 40, who had used a varying dose of ERT with varying durations. As can be seen from Table III, the expected lifetime risks of breast cancer depend strongly on the age of $\mathrm{BO}$, and the duration of ERT. With older age of BO and longer duration of ERT the expected lifetime risk of breast cancer increases and even exceeds the risk in women with natural menopause. Thus, in these studies the relatively high breast cancer risk in this predominant subgroup (women with BO after age 40 , and mixed durations of ERT) may have dominated the effect of $\mathrm{BO}$ in the small subgroup of women with early age of $B O$.

In women with a family history of breast cancer (especially early breast cancer), the risk of developing breast cancer is elevated. For instance, women with both a mother and a sister who have had breast cancer have a very high risk for the disease; the risk of breast cancer in women with an affected mother and sister was found to be $50 \%$ by 65 years of age. In these women, the prophylactic effect of $\mathrm{BO}$ on breast cancer risk may be substantial.

When BO with subsequent ERT is chosen, there is the issue of the duration of the ERT. It is feared that long lasting ERT (after age 50) increase breast cancer risk. In Table $\mathrm{V}$ the increase in lifetime breast cancer risks with prolonged ERT is presented (calculated in the same way as the above risks, see Appendix). Such an increase in breast cancer risk is not a part of the issue of whether or not $\mathrm{BO}$ should be performed in the premenopauzal woman because it relates to hormone replacement therapy after age 50 and not to estrogen suppletion to compensate for the premenopauzal hypoestrogenic effect of $\mathrm{BO}$. 


\section{TABLE V}

The estimated increase in lifetime breast cancer risk with prolonged ERT, relative to ERT until age 50

\begin{tabular}{lll}
\hline $\begin{array}{l}\text { Age at } \\
\text { hysterectomy }\end{array}$ & \multicolumn{2}{l}{$\begin{array}{l}\text { The estimated increase in lifetime } \\
\text { breast cancer risk (\%) }\end{array}$} \\
\cline { 2 - 3 } & ERT until 60 & ERT lifelong \\
\hline 30 & 0.5 & 1.2 \\
35 & 0.7 & 1.7 \\
40 & 0.9 & 2.3 \\
45 & 1.1 & 2.7 \\
\hline
\end{tabular}

\section{Discussion}

For women who do not have one or more first degree relatives with ovarian cancer or breast cancer, the potential bencfit of $\mathrm{BO}$ is the reduction of ovarian and breast cancer risks (Tables I and IV). These benefits must be weighed against the disadvantages of $\mathrm{BO}$, namely the psycho-emotional impact of losing the ovaries, the unfrequent complications of surgery and the risk of cardiovascular disease and osteoporosis when compliance with estrogen therapy is incomplete.

For the individual patients, the meaning of these potential benefits may be illustrated by the following information. The average life expectancy of a 40 -year-old woman in the Netherlands is 41 years. If she belongs to the approximately $1.6 \%$ of her age group who will acquire ovarian cancer in the course of their lives, the onset may be at any age, but a "typical" age of acquiring the disease might be 65-69 (see Table II, last column) with a 5-year survival rate of approximately $35 \%$. Likewise, if she belongs to the approximately $10 \%$ of her age group who will acquire breast cancer in the course of her life, the age of onset cannot be predicted but a "typical" age of onset could be at 65-69 years with a 5-year survival rate of $62 \%$.

Our theoretical calculations suggest that in women with an early age of $\mathrm{BO}$, the protective effect of $\mathrm{BO}$ on breast cancer risk may be retained despite subsequent non-low-dose ERT. If this is true for non-low-dose ERT, this will even be more so for low-dose ERT. These hypotheses remain to be validated.
Provided compliance is good, low-dose ERT prevents the atherosclerotic effects and osteoporosis which result from BO $[6,15,18,29]$. However, when compliance is less than perfect, the increased risk of coronary heart disease and osteoporosis outweighs the benefits of reduced ovarian and breast cancer risk [28]. Thus the attending physician must motivate the patient and ensure compliance by careful follow-up.

The incidence figures of ovarian and breast cancer vary across countries. In the present article, the data on ovarian and breast cancer risk to the Dutch population. The age-specific and cumulative lifetime incidence rates of ovarian cancer and breast cancer in The Netherlands are not very different from other Western countries $[36,37]$. For other populations, ovarian and breast cancer risks can be computed using the samc methods as above.

It is hoped that the provided data may help the woman and the attending physician in making the right choice on whether or not prophylactic $\mathrm{BO}$ should be performed.

\section{Acknowledgements}

We thank Prof. J.H.H. Thijssen (Laboratory for Endocrinology, Academic Hospital Utrecht), Dr. J.W.R. Nortier (Deaconess Hospital Utrecht), Dr. H.F.A Vasen (Foundation for the Detection of Hereditary Tumours) for reading the manuscript and their valuable advice, Ronald Damhuis (Comprehensive Cancer Centre Rotterdam) for providing the data on lifetime risks of ovarian cancer and Ingrid Wilschut for secretarial assistance.

Appendix: The method of calculating the risks of breast cancer

The potential impact of BO with subsequent ERT was estimated by using a comprehensive mathematical model which was based on epidemiological incidence data and cell kinetic factors influencing the carcinogenesis of the breast [21]. In most tumours, the incidence rate increases exponentially with age, while the rate of increase is constant. Thus, when the logarithm of incidence is plotted against the logerithm of age, the curve 
is a straight line. In contrast, in breast cancer the incidence does not increase with a constant rate through all ages: after menopause the rate of increase declines. Accordingly in the descriptive mathematical model, incidence rates of breast cancer increase by an age-dependent factor $M(T)$ (the incidence age is denoted by $T) . M(T)$ can be interpreted as the "relevant age" of the tissue [21], resulting from the exposure of breast cells to estrogen in the previous life years [22]. The incidence at age $T$ is described by the equation $I(T)=a \cdot\{M(T)\}^{4.5}$. After menarche, in each year the brcast cclls arc exposed to estrogen and the effect of this exposure (proliferative activity) during a life year is expressed in terms of an "effective yearly mitotic rate" $m(t)$. (The age of exposure, in years, is denoted by $t$.) During life, the effects of exposures in previous life years accumulate and thus at a certain age $T$, the combined effect of previous exposures is represented by the sum of these effective mitotic rates. In algebraic terms, $M(T)$ is the sum of all the values of $m(t)$ in previous life years.

An excellent description of the age-incidence curve and the major known risk factors was realized by assigning the following values to $m(t)$ [22]:

$m(t)=0 \quad$ from birth to menarche

$=1$ from menarche (taken as age 13) to first full-term pregnancy (FFTP) (taken as occurring at age 22$) ; 2.2$ is added to $m(t)$ for the year in which FFTP occurs

$=0.7$ from FFTP to age 40

$=0.105$ after natural menopause (last menstrual period, taken as occurring at age 50); $m(t)$ declines linearly from 40 to menopause.

The lower values of $m(t)$ after natural menopause correspond with the diminished increase in the incidence rate.

The prospective lifetime risk after BO with subsequent low dose ERT was estimated as follows. First, the total effective mitotic rate $M(T)$ at age $T$ was calculated as the sum of the effective mitotic rates $m(t)$ in previous life years, using the values of $m(t)$ which are given above. As to the years after $\mathrm{BO}$, when ERT is uscd the yearly mitotic rate $m(t)$ was calculated as follows. After BO with subsequent ERT, the yearly mitotic rate $m(t)$ has the base line value of 0.105 (no additional breast cancer risk from ERT) with a correction term, which represents the effect of ERT on breast cancer risk. The effect of ERT was translated into an increase of $m(t)$ from 0.105 to 0.212 as follows. For oophorectomized women, the mean proportional increase in risk for each year of estrogen use (various doses) was calculated as 0.028 (95\% CI $0.010-0.046)$, expressed on a log-scale with base $e$ (after removal of statistical outliers) in a meticulous meta-analysis [30] et al., 1991), based on reported studies [7,12-14,25,34]. This estimated risk corresponds with a relative risk of $e^{0.028 * 20}=1.75$ for 20 years of ERT use. Using the above equations, this relative risk was translated by us into an increase of the yearly mitotic rate $m(t)$ from 0.105 to 0.212 ; the method of this calculation is described elsewhere [22]. Using this figure, $M(T)$ was calculated as the sum of $m(t)$ in previous life years.

Second, using the estimated $M(T)$, the incidence rate at age $T$ [denoted as $I(T)$ ] was calculated using the equation:

$I(T)$ after $\mathrm{BO}=\{I(T)$ in general population $\}$

$$
\times \frac{M(T) \text { after } \mathrm{BO}}{M(T) \text { in general population }} 4.5
$$

This equation is based on the formula $I(T)=$ $a\{M(T)\}^{4.5}$ where $a$ is constant $[21,22]$.

The values of $I(T)$ (the age-specific incidence rates of breast cancer) were computed using the data from the Regional Cancer Registries of three Comprehensive Cancer Centres (IKMN, IKR, IKZ); these registries cover adjacent geographically defined areas and are virtually population-bases ( 3.6 million inhabitants, $25 \%$ of the whole country).

Finally, from these age-specific incidence rates $I(T)$ the prospective lifetime risks were calculated using actuarial life table analysis and the data on age-specific mortality and life expectancy from the Dutch Central Bureau of Statistics.

\section{References}

1 Annegers JF, Strom H, Decker DG et al. Ovarian cancer. Incidence and case-control study. Cancer 1979;43:723-29.

2 Brinton LA, Hoover RN, Szklo $M$ et al. Menopausal estrogen use and risk of breast cancer. Cancer 1981;47: 2517-22.

3 Balert-Locht HR, Coebergh JWW, Hop WCJ et al. Improved pognosis of ovarian cancer in the Netherlands during the period 1975-1985. Gynecol Oncol 1991;42:3-8.

4 Dupont WD, Page DL. Menopausal estrogen replacement therapy and breast cancer. Arch Intern Med 1991;151:6772 .

5 Eijkeren van MA, Graaf de J, Etten van F. Familial ovarian cancer: a case report. In press.

6 Gennari C, Agnusdei Nardi P, Civitelli R. Estrogen preserves a normal intestinal responsiveness to 1,25-dihy- 
droxyvitamin $\mathrm{d} 3$ in oophorectomized women. J Clin Endocrinol Metab 1990;71:1288-1293.

7 Hiatt RA, Bawol R, Friedman GD et al. Exogeneous estrogen and breast cancer after bilateral oophorectomy. Cancer 1984;54:139-44.

8 Hulka BS. Replacement estrogens and risk of gynecologic cancers and breast cancer. Cancer 1987;60:1960-1964.

9 Hulka BS. When is the evidence for 'no association' sufficient?. JAMA 1984;252:81-82.

10 Hulka BS, Chambless LE, Deubner DC et al. Breast cancer and estrogen replacement therapy. Am J Obstet Gynecol 1982;143:638-644.

11 Irwin $\mathrm{K}$, Weiss $\mathrm{N}$, Lee $\mathrm{N}$ et al. Tubal sterillization, hysterectomy and the subsequent occurrence of epithelial ovarian cancer, Abstract presented at the twenty-third annual meeting of the Society for Epidemiologic Research. Am J Epidemiol 1990;132:777.

12 Jick H, Walker AM, Watkins RN et al. Replacement estrogens and breast cancer. Am J Epidemiol 1980;112: $586-94$.

13 Kaufman DW, Miller DR, Rosenberg L et al. Noncontraceptive estrogen use and the risk of breast cancer. JAMA 1984;252:63-7.

14 Kelsey JL, Fisher DB, Holford TR et al. Exogeneous estrogens and other factors in the epidemiology of breast cancer. J Natl Cancer Inst 1981;67:327-33.

15 Lindsay R, Hart DM, Clark DM. The minimum effective dose of estrogen for prevention of postmenopausal bone loss. Obstet Gynecol 1984;63:759-763.

16 Lynch HT, Albano WA, Lynch JF et al. Surveillance and management of patients at high genetic risk for ovarian carcinoma. Obstet Gynecol 1982;59:589-596.

17 Lynch HT, Conway T, Lynch J. Hereditary ovarian cancer. In: Sharp F, Mason WP, Leake RE, eds. Ovarian cancer London: Chapman and Hall Medical, 1990;7-19.

18 Paganini-Hill A, Ross RK, Gerkins VR, Henderson BE, Arthur M, Mack TM. Menopausal estrogen therapy and hip fractures. Ann Intern Med 1981;95:28.

19 Parrish HM, Carr CA, Hall DG et al. Time interval from castration in premenopausal women to development of excessive coronary atherosclerosis. Am J Obstet Gynecol 1967;99:155-62.

20 Persson I, Adami HO, Bergström $\mathbf{R}$ et al. Survival in women receiving hormone replacement therapy. A record-linkage study of a large population-based cohort. $\mathbf{J}$ Clin Epidemiol 1990;43:677-685.

21 Pike MC, Henderson BE, Krailo MD et al. Breast cancer in young women and use of oral contraceptives: possible modifying effects of formulation and age at use. Lancet 1983;ii:926-930.

22 Pike MC, Ross RK, Lobo RS et al. LHRH antagonists and the prevention of breast and ovarian cancer. $\mathrm{Br} \mathrm{J}$ Cancer 1989;60:142-148.

23 Ponder BAJ, Easton DF, Peto J. Risk of ovarian cancer associated with a family history: Preliminary report of the OPCS study. In: Sharp F, Mason WP, Leake RE, eds. Ovarian cancer London: Chapman and Hall Medical, 1990;3-6.

24 Rosenberg L, Hennekens CH, Rosner B et al. Early menopause and the risk of myocardial infarction. Am $\mathbf{J}$ Obstet Gynecol 1981;139:47-51.

25 Ross RK, Paganini-Hill A, Gerkins VR et al. A case-control study of menopausal estrogen therapy and breast cancer. JAMA 1980;243:1635-1639.

26 Schweppe KW, Beller FK Zur Frage der prophylaktischen Ovarektomie. Geburtsh Frauenheilkd 1979;39:1024-32.

27 Siddle N, Sarrel P, Whitehead M. The effect of hysterectomy on the age at ovarian failure: identification of a subgroup of women with premature loss of ovarian function and literature review. Fertil Steril 1987;47:94-100.

28 Speroff T, Dawson NV, Speroff L et al. A risk-benefit analysis of elective bilateral oophorectomy: effect of changes in compliance with estrogen therapy on outcome. Am J Obstet Gynecol 1991;164:165-74.

29 Stampfer MJ, Colditz GA, Willett WC et al. Postmenopausal estrogen therapy and cardiovascular disease. Ten-year follow-up from the Nurses' Health Study. N Engl J Med 1991;325:756-762.

30 Steinberg KK, Thacker SB, Smith SJ et al. A meta-analysis of the effect of estrogen replacement therapy on the risk of breast cancer. JAMA 1991;265:1985-1990.

31 Studd J. Prophylactic oophorectomy. Br J Obstet Gynaecol 1989;96:506-509.

32 Tobachman JK, Tucker MA, Kase R et al. Intraabdominal carcinomatosis after prophylactic oophorectomy in ovarian cancer prone famlies. I ancet 1982;ii:795-797.

33 Vessey MV. Exogeneous hormones in the aetiology of cancer in women. J R Soc Med 1984;77:542-549.

34 Wingo PA, Layde PM, Lee NC et al. The risk of breast cancer in postmenopausal women who have used estrogen replacement therapy. JAMA 1987;209-215.

35 Schwartz AG, King MC, Belle SH et al. Risk of breast cancer to relatives of young breast cancer patients. J Natl Cancer Inst 1985;75:665-668.

36 Cutler SJ, Young JL. Third national cancer survey: incidence data National Cancer Institute, Monograph 41. US Department of Health Education and Welfare. USA: National Cancer Institute, Bethesda MD, 1975.

37 Parkin DM. Cancers of the breast, endometrium and uvary: geographic correlations. Eur $\mathrm{J}$ Cancer Clin Oncol 1989;25:1917-1925. 